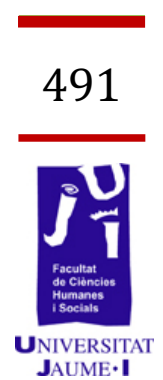

\title{
Trencant el model hegemònic Actitud dels consumidors davant d'una oferta de diaris escrits en llengua valenciana
}

Silvia Marcos García

silvia.mg.7@gmail.com 
L'Estatut d'Autonomia de la Comunitat Valenciana reconeix el castellà i el valencià com les dues llengües oficials del territori. No obstant això, aquesta última sempre ha estat relegada de molts àmbits. Entre els més importants es troben els mitjans de comunicació, on el seu ús és pràcticament nul degut, sobretot, al domini dels grans grups de comunicació aliens a la regió.

Davant d'aquest panorama, aquest article té com a objectiu analitzar el context comunicatiu valencià i, especialment, la seva relació amb un agent en concret, el consumidor. Així, partint d'una enquesta quantitativa a diferents grups d'edat i sexe, s'examina la seva percepció del valencià, els seus hàbits en el consum de premsa i l'actitud davant d'una possible oferta de diaris en valencià.

Com a resultat es demostra que, a pesar del fet que la societat es considera culpable de la situació de marginació que viu la llengua, mostra alhora una actitud completament positiva quant a la utilitat $i$ importància del valencià i la seva utilització en la premsa. Especialment seran els joves qui recolzen aquesta última idea, un fet a destacar tenint en compte el seu baix nivell de lectura de diaris en paper.

Paraules clau: premsa, valencià, consumidors, Castelló, normalització lingüística

\section{Introducció}

\subsection{La importància dels mitjans de comunicació en llengua pròpia}

Els mitjans de comunicació van néixer com una eina mitjançant la qual les persones podem transmetre i rebre informació. Des que van aparèixer els primers diaris al segle XVIII fins avui, amb multitud de formats on triar, aquests instruments permeten una contínua connexió amb els diferents esdeveniments polítics, econòmics i socials que es produeixen, tant al nostre voltant, com a escala internacional. Ha estat, per tant, el primer element capaç de crear una societat global on no existeixen fronteres ni límits quant a comunicació es refereix.

Per aquest motiu, el treball dut a terme pels mitjans de comunicació es troba més enllà del mer traspàs d'informació. Aquests són un poderós element de socialització a través del qual les persones poden tenir al seu abast una infinitat d'idees, opinions, valors i creences. Tal com afirma Joan Viñas i Sales «els mitjans de comunicació són els que ens informen però també els que ens mostren les diferents visions de la quotidianitat» (2008: 9).

Així doncs, s'han convertit en el pilar fonamental per al desenvolupament, tant de les persones a escala individual, com de qualsevol comunitat. Més en aquelles que comparteixen un dels trets més importants per a qualsevol comunicació verbal, l'idioma. Els mitjans de comunicació "són instruments de primer ordre en els processos de 
normalització lingüística perquè, en utilitzar una llengua, la difonen, en mostren la utilitat, la mantenen viva i també li donen prestigi» (Castellano, 2008: 253). En resum, fomenten la cohesió social i territorial de les comunitats, vinculen la llengua en les seves realitats socials i potencien la seva validesa i funcionalitat quotidiana (Martínez, 2010: 7).

La Comunitat Valenciana és un dels territoris d'Espanya on està present aquesta llengua pròpia, el valencià. No obstant això, el seu panorama comunicatiu es troba en una situació cada vegada més difícil. La crisi econòmica i de model, així com la falta de suport polític i social cap a la llengua, fan que el futur dels mitjans de comunicació en valencià sigui cada vegada més incert. Sobretot, en el cas de la premsa, on no solament està present el problema de la llengua, sinó també el del seu consum enfront d'altres mitjans com Internet.

La raó d'aquest treball es basa, per tant, en conèixer quin és el context que avui viuen els mitjans de comunicació escrits i quin podria ser el seu futur tenint en compte l'actitud del consumidor davant d'una oferta escrita en valencià. Una investigació, per tant, necessària ja que fins ara els estudis s'han centrat únicament en l'estructura dels mitjans comunicatius valencians i l'ús que fan cadascun d'ells de la llengua que identifica al territori.

\subsection{Situació del valencià als mitjans de la Comunitat Valenciana: el cas de la premsa}

El context del País Valencià quant als mitjans de comunicació en Ilengua pròpia és delicat, tot degut principalment a tres circumstàncies.

La primera d'elles són les polítiques de comunicació. A la Comunitat Valenciana aquestes són completament escasses, ja que no hi ha suficients regulacions lingüístiques per a donar suport al valencià per part de la Generalitat Valenciana. De fet, a excepció del pressupost que es destinava a Ràdio Televisió Valenciana, «cap mitjà de comunicació públic o privat en valencià ha rebut un suport adequat» (Martínez, 2010: 84). En concret, els diners que el Govern valencià va assignar al canal de televisió i ràdio públics en 2012 van sumar un total de 112,6 milions d'euros. Una xifra que, no obstant això, queda molt per sota de la que destinen altres Governs de comunitats autònomes amb llengua pròpia, com són Catalunya o el País Basc (Zabaleta et al.,2012).

Tant en la comunitat catalana com en la basca, el finançament públic suposa al voltant de la meitat dels ingressos dels mitjans locals en llengua autòctona. En concret, mentre que a Catalunya el pes d'aquest pressupost és d'un 65,8\%, al País Basc els diners públics arriben al 46,2\% (Zabaleta et al.,2012). Així doncs, «cal que els nostres administradors prenguin consciència que cal comunicar en valencià per a fer normal allò que als nostres pobles, viles i ciutats és comú des de fa alguns anys i que, de vegades, mai no havia deixat de ser-ho: comunicar-se en valencià» (Castellano, 2008: 252).

La segona raó prové dels mateixos treballadors donat que al País Valencià hi ha hagut una completa manca d'unitat vertebradora per part dels mitjans existents a favor de la llengua. (Ferrando, 1990). Els únics casos 
són la Xarxa d'Emissores Municipals Valencianes creada a 2006 i l'Associació de Publicacions Periòdiques Valencianes a 2009. Organitzacions, no obstant això, molt recents i amb poc de pes comparades amb altres com l'Associació Catalana de Premsa Comarcal, amb 25 anys de trajectòria, o l'Associació de Publicacions Periòdiques en Català, amb 20 anys (Martínez, 2010).

Per últim, l'actitud col-lectiva dels valencians de cara al valencià caracteritzada per la seva falta de suport a l'idioma i la poca pressió social davant les escasses polítiques lingüístiques, han fet que la llengua sigui un tema secundari (Ferrando, 1990). De fet «cada dia s'observa certa actitud social i empresarial que demostra que encara no hi ha una consciència clara d'aquesta realitat» (Castellano, 2008: 251).

Aquestes condicions han condicionat, per tant, que avui en dia no pugui haver cap mitja de comunicació consolidat en valencià, doncs tant la falta de suport polític, econòmic i social no ho permeten. Un fet molt sorprenent especialment en la premsa, que compta amb tants anys d'existència.

Des dels inicis del segle XXI, el País Valencià no té cap periòdic en Ilengua autòctona. Tampoc hi ha cap diari de periodicitat diversa que avui en dia hagi aconseguit nivells acceptables de difusió en tot el territori valencià (Martínez,2010). De fet, quan a la democràcia es van subhastar diaris com Levante, Información o Mediterráneo, aquests van passar a mans d'empreses privades de grans grups castellanoparlants. Entre altres, Editorial Premsa Ibèrica S.A va adquirir Llevant-EMV i Informació, el Grup $Z$ va comprar Mediterráneo i Ciutat d'Alcoi i el Grup Vocento va integrar a la seva empresa a Las Provincias i La Verdad. D'aquesta forma es va perdre l'oportunitat de fer viable qualsevol iniciativa periodística que pogués reflectir el valencià i la seva tradició (Beltran, 2008).

Per aquest motiu, avui en dia "la premsa en valencià és efímera, fluctuant i precària i funciona gràcies al voluntarisme dels promotors i periodistes que estan al capdavant de petites capçaleres setmanals o mensuals, localitzades en petites comarques» (Martínez, 2010:59). De fet, edicions en paper de periòdics tan importants com El Punt o L'Avanç ja han desaparegut a la comunitat, quedant solament la seva edició en digital.

A més, l'esforç de les grans capçaleres a favor de la utilització de la llengua valenciana en les seves edicions és mínim, doncs la seva presència queda reduïda a articles d'opinió o a determinades pàgines que es publiquen eventualment per motius de festes, cultura o educació (Martínez,2010). Un dels casos més significatius és el de Levante EMV, un dels que fa major ús del valencià gràcies al seu suplement setmanal, de nom Aula, dedicat a l'àmbit escolar i educatiu. A més, diàriament publica una pàgina denominada Panorama (abans El Dau), que tracta temes de cultura i combina articles escrits en castellà i valencià.

Solament revistes especialitzades com Saó o El Temps, íntegrament escrites en valencià, han aconseguit mantenir-se amb un relatiu èxit a l'estructura informativa valenciana (Martínez, 2010). El Temps, en primer lloc, es tracta d'un setmanari amb dues dècades d'existència i una 
cobertura informativa que arriba al conjunt de territoris de llengua catalana però amb una difusió inferior dels 10.000 exemplars. Saó, per altra banda, és una revista mensual considerada la degana de les publicacions valencianes en català (Beltran, 2008).

Dit això, es pot dir que la premsa en castellà domina profundament el panorama informatiu valencià. De fet, segons I'OJD, els diaris de més difusió a la Comunitat Valenciana sumen una mitjana de 230.325 exemplars, tots ells escrits en castellà. Fins i tot, la premsa en aquest idioma és la més popular a les zones on el valencià està més present. Entre elles, Castelló, segona província on més s'utilitza aquesta llengua i on s'ha dut a terme la recerca d'aquesta investigació.

Tal com assenyala l'Informe de Coneixement i Ús del Valencià fet per la Conselleria d'Educació de 2010, sis de les vuit comarques castellonenques es defineixen valenciano-parlants, excepte Alt Millars i Alt Palància. D'aquestes sis, el $58,7 \%$ dels seus habitants reconeix llegir-ho perfectament, 34,5\% escriure-ho, 80,5\% entendre-ho i $61,7 \%$ parlar-ho.

Malgrat d'això, en aquest territori, com ocorre en la resta de la Comunitat Valenciana, els diaris amb més difusió són, o bé grans capçaleres nacionals amb seccions provincials, o diaris exclusius de la província escrits en castellà. En concret, el que major difusió té és Mediterráneo, amb 18.718 exemplar, segons la OJD. Es tracta de l'únic diari nascut i difós únicament a la província i pràcticament centrat en informació relativa a aquesta.

Seguidament, el periòdic més consumit és l'edició provincial de El Mundo, amb 3.709 exemplars. La redacció d'aquest diari, encara que pertany a un periòdic de tiratge nacional, se situa a Castelló i la informació apareix publicada com un petit quadern dins del mateix exemplar d'edició estatal.

El tercer és Levante de Castelló que, com els anteriors, té la seva redacció a la capital de la província però, igual que Mediterráneo, està completament editat amb notícies de les diferents comarques i ciutats de Castelló, de forma que es completament independent a l'edició de Levante-EMV.

Finalment, Las Provincias també disposa d'informació relativa a Castelló. No obstant això, la seva redacció se situa a València. En aquest cas, les notícies de la província són incloses en l'edició autonòmica. Quant als exemplars, a Castelló el total de difusió suma 718.

Aquesta situació revela que, encara que el valencià ha arribat a normalitzar-se després de molts segles de marginació en àmbits com l'acadèmic, universitari i cultural, encara no ha arribat a nivells suficients quant als mass media es refereix per tal que es pugui garantir la seva supervivència social (Beltran, 2008: 328). De fet, en aquests casos, utilitzar el valencià pareix un acte de resistència que va en contra dels hàbits de gran part de la població. Avui en dia «ser periodista en valencià suposa una doble feina, la normal com a professional i la de convèncer tothom que en valencià es pot fer informació més enllà dels temes folklòrics» (Castellano, 2008: 255). 


\section{Objectius}

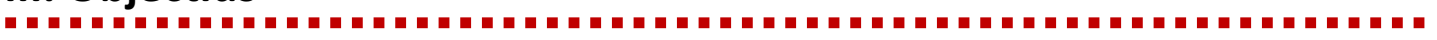

Els objectius d'aquesta recerca són:

1) Conèixer els hàbits de la població de Castelló quant a l'ús i percepció

del valencià

2) Dilucidar la seva rutina de consum d'informació i la seva percepció i actitud enfront d'una oferta de diaris escrits en valencià a la província de Castelló.

Les hipòtesis, d'altra banda, són les següents: H1. La societat, a causa de factors com la globalització, fa un ús cada vegada menor del valencià a favor d'altres com el castellà. H2. Aquest desplaçament de la llengua fa que la societat es mostri reticent a consumir informació en valencià, especialment, de diaris escrits completament en aquest idioma.

\section{Material i mètode}

El disseny metodològic d'aquesta investigació es basa en l'aplicació d'una enquesta quantitativa amb la qual s'han pretès obtenir dades objectives, així com aspectes més subjectius basats en opinions i actituds dels entrevistats.

El total d'enquestes realitzades ha sigut de 71 , en les quals s'ha utilitzat com a variables dependents el sexe i l'edat. Tenint en compte aquest últim paràmetre, s'ha fet una divisió en quatre blocs: menors de 18 anys, entre 18 i 30, entre 30 i 55 i majors de 55 . El motiu d'aquesta elecció es correspon amb les diferents èpoques de creixement $\mathrm{i}$ maduresa amb els quals s'identifica cada període i que fan que cada grup tingui unes determinades actituds i, en concret, formes de consum d'informació. Quant al sexe, els resultats han revelat que un $53,52 \%$ correspon a enquestes realitzades per dones i un $46,57 \%$ per homes.

El treball de camp, d'altra banda, s'ha desenvolupat durant el mes d'abril de 2013, mitjançant un procediment d'entrevista personal cara a cara. En concret, les zones on s'han repartit les enquestes són Castelló de la Plana, Onda, Suera, La Serra d'En Galceran i Benicàssim, obtenint així dades de diferents punts de Castelló, província on destaca un ús alt del valencià.

Finalment, quant a l'estudi es refereix, aquest s'ha basat en una sèrie de preguntes de resposta única i múltiple, el contingut de les quals tenia com a finalitat conèixer tant els hàbits dels enquestats, com les seves opinions. Les variables independents en aquesta recerca han estat, en primer lloc, el costum quant a l'ús del valencià a l'hora de parlar, llegir o escriure, així com el consum de premsa, buscant saber si llegeixen habitualment, en quin idioma ho fan o quin diari de la província de Castelló trien per informar-se. En segon Iloc, quina és la valoració que els enquestats fan sobre la premsa en valencià, si aquesta hauria d'augmentar la seva oferta, si Internet fomentaria l'ús d'aquest idioma en la premsa i si consumirien informació en la xarxa que estigués escrita en aquest idioma. 
5.1 Coneixement del valencià i freqüència d'ús a l'hora de parlar, escriure illegir

Tal com va reflectir en 2010 l'Informe de Coneixement i Ús del Valencià fet per la Conselleria d'Educació, el coneixement del valencià a la província de Castelló es molt elevat.

Unes dades que corroboren els resultats d'aquesta investigació, que revelen que la totalitat dels enquestats entén sense cap dificultat el valencià, un 55,7\% l'utilitzen sempre a l'hora de parlar, un 45,7\% Ilegeix continguts en aquest idioma i, finalment, un $30,08 \%$ ho empra per escriure (taula 1). En canvi, molt pocs són els que es mostren reticents en la seva utilització. No obstant això, sí que hi ha algunes dades a les quals cal prestar especial atenció.

La variable d'edat corrobora que, a mesura que els anys augmenten, I'ús d'aquesta llengua es va reduint, donat que, mentre que la mitjana de joves menors de 18 anys que parla sempre el valencià és de $56,25 \%$, la dels majors de 55 anys es redueix fins al 36,5\% (taula 1). Un fet que es repeteix també en les altres capacitats. No obstant això, la raó d'aquesta situació es deu al fet què la totalitat dels menors de 18 anys i molts dels joves d'entre 18 i 30 estaven realitzant els seus estudis en centres de la província de Castelló.

Aquest fet suposa que tots ells utilitzen el valencià durant les hores lectives donat que tota o part de les assignatures estan impartides en aquest idioma. Per tant, resulta comprensible que la utilització del valencià sigui molt més habitual en els joves que no en aquells que superen els 55 anys. 
Taula 1. Coneixement i ús del valencià (\%)

\begin{tabular}{|c|c|c|c|c|c|c|c|c|c|}
\hline \multicolumn{10}{|c|}{ Entén el valencià } \\
\hline & Total & \multicolumn{2}{|c|}{$<18$ anys } & \multicolumn{2}{|c|}{ 18-30 anys } & \multicolumn{2}{|c|}{ 30-55 anys } & \multicolumn{2}{|c|}{$<55$ anys } \\
\hline & & D & $\mathbf{H}$ & D & $\mathbf{H}$ & D & $\mathrm{H}$ & D & $\mathbf{H}$ \\
\hline Mai & - & - & - & - & - & - & - & - & - \\
\hline Alguna vegada & - & - & - & - & - & - & - & - & - \\
\hline Sempre & 100 & 100 & 100 & 100 & 100 & 100 & 100 & 100 & 100 \\
\hline \multicolumn{10}{|c|}{ Parla en valencià } \\
\hline & Total & \multicolumn{2}{|c|}{$<18$ anys } & \multicolumn{2}{|c|}{$18-30$ anys } & \multicolumn{2}{|c|}{ 30-55 anys } & \multicolumn{2}{|c|}{$<55$ anys } \\
\hline & & D & $\mathbf{H}$ & D & $\mathbf{H}$ & D & $\mathrm{H}$ & D & $\mathbf{H}$ \\
\hline Mai & 14,5 & 20 & 12,5 & 27,3 & - & 14,9 & 9,1 & 33,3 & - \\
\hline Alguna vegada & 29,7 & 30 & 25 & 27,3 & 20 & 7,14 & $\begin{array}{c}36 \\
4\end{array}$ & 66,7 & 25 \\
\hline Sempre & 55,7 & 50 & 62,5 & 45,4 & 80 & 78,6 & $\begin{array}{c}54 \\
5\end{array}$ & - & 75 \\
\hline \multicolumn{10}{|c|}{ Llegeix en valencià } \\
\hline & Total & \multicolumn{2}{|c|}{$<18$ anys } & \multicolumn{2}{|c|}{$18-30$ anys } & \multicolumn{2}{|c|}{ 30-55 anys } & \multicolumn{2}{|c|}{$<55$ anys } \\
\hline & & D & $\mathbf{H}$ & D & $\mathrm{H}$ & D & $\mathrm{H}$ & D & $\mathbf{H}$ \\
\hline Mai & 8 & - & - & 18,18 & - & 14,3 & 9,1 & - & 25 \\
\hline Alguna vegada & 46 & 50 & 37,5 & 27,3 & 30 & 18,6 & 36,4 & 100 & 50 \\
\hline Sempre & 46 & 50 & 62,5 & 54,5 & 70 & 57,15 & 54,5 & - & 25 \\
\hline \multicolumn{10}{|c|}{ Escriu en valencià } \\
\hline & Total & \multicolumn{2}{|c|}{$<18$ anys } & \multicolumn{2}{|c|}{ 18-30 anys } & \multicolumn{2}{|c|}{ 30-55 anys } & \multicolumn{2}{|c|}{$<55$ anys } \\
\hline & & D & $\mathrm{H}$ & D & H & D & $\mathrm{H}$ & D & $\mathbf{H}$ \\
\hline Mai & 24,2 & - & - & 45,4 & - & 21,4 & $\begin{array}{c}18 \\
2\end{array}$ & 33,3 & 75 \\
\hline Alguna vegada & 41,8 & 70 & 50 & 27,3 & 30 & 28,6 & $\begin{array}{c}36 \\
7\end{array}$ & 66,6 & 25 \\
\hline Sempre & 30,08 & 30 & 50 & 23,3 & 70 & 50 & $\begin{array}{c}45 \\
4\end{array}$ & - & - \\
\hline
\end{tabular}

Elaboració pròpia

\subsection{Valoració de la utilitat del valencià i del seu reconeixement}

La recerca prèvia ha demostrat que el context en el qual es troba el valencià és molt difícil ja que amb prou feines compta amb suficient presència en els mitjans de comunicació.

Tot i això, les dades revelen que un 70,5\% dels enquestats consideren que el valencià és un idioma necessari i útil per a la societat. En concret, el grup que considera més pràctica aquesta llengua és el de majors de 55 anys (taula 2). Un resultat molt revelador donat que, com s'ha vist en el punt anterior, són els que menor ús fan de l'idioma.

Cal afegir que moltes d'aquestes persones han viscut en un context on no estava permès emprar aquesta llengua en àmbits com l'acadèmic, administratiu i, molt menys, als mitjans de comunicació. La dictadura de Francisco Franco va organitzar Espanya com una unitat nacional en la qual solament es respectava el castellà com a llengua oficial. Per contra, llengües com el català, gallec o basc quedaven limitades a l'àmbit familiar. 
Per tant, resulta destacable que un grup que a penes ha conviscut amb aquest idioma sigui el que més el defensa.

Taula 2. Opinió sobre la utilitat i necessitat del valencià a la societat (\%)

\begin{tabular}{|c|c|c|c|c|c|c|c|c|c|}
\hline & Total & \multicolumn{2}{|c|}{$<18$ anys } & \multicolumn{2}{|c|}{$18-30$ anys } & \multicolumn{2}{|c|}{ 30-55 anys } & \multicolumn{2}{|c|}{$<55$ anys } \\
\hline & & D & $\mathrm{H}$ & $\bar{D}$ & $\mathrm{H}$ & $\bar{D}$ & $\bar{H}$ & $\bar{D}$ & $\mathrm{H}$ \\
\hline Útil i necessari & 70,5 & 90 & 50 & 54,5 & 80 & 92,2 & 72,7 & 100 & 75 \\
\hline $\begin{array}{l}\text { No útil ni } \\
\text { necessari }\end{array}$ & 23,1 & 10 & 50 & 45,4 & 20 & 7,14 & 23,7 & 0 & 25 \\
\hline
\end{tabular}

Una altra qüestió important es troba en el reconeixement que té el valencià a Castelló. Com s'ha vist, encara que hi ha moltes persones que l'empren amb assiduïtat, la seva utilització total encara és escassa i, fins i tot, hi ha casos en els quals ni tan sols es considera suficientment útil. Una realitat que ha demostrat aquesta anàlisi, on un $59,5 \%$ dels enquestats considera que el valencià no està suficientment reconegut, no solament en els mitjans de comunicació, sinó en la resta d'àmbits (taula 3).

Taula 3. Opinió sobre el reconeixement del valencià a Castelló (\%)

\begin{tabular}{|c|c|c|c|c|c|c|c|c|c|}
\hline & Total & \multicolumn{2}{|c|}{$<\mathbf{1 8}$ anys } & \multicolumn{2}{|c|}{$\mathbf{1 8 - 3 0}$ anys } & \multicolumn{2}{|c|}{$\mathbf{3 0 - 5 5}$ anys } & \multicolumn{2}{c|}{$<55$ anys } \\
\hline & & D & H & D & H & D & H & D & H \\
\hline Reconegut & 40,5 & 50 & 62,5 & 63,6 & 20 & 57,14 & 45,4 & - & 25 \\
\hline No reconegut & 59,5 & 37,5 & 36,7 & 36,7 & 80 & 42,8 & 54,5 & 100 & 75 \\
\hline
\end{tabular}

Elaboració pròpia

Igual que ocorria en l'anterior cas, les variables d'edat demostren que el grup més crític és el de majors de 55 anys, ja que són els que més creuen que el valencià no està suficient reconegut a la província (taula 3).

Per contra, en aquest cas els joves menors de 18 anys són els que més a favor es mostren davant de l'aparent normalització del valencià, donat que el $56,25 \%$ opina que sí que està reconegut a la província. No obstant això, en aquest cas cal destacar que aquest grup d'edat es mou majoritàriament per l'àmbit educatiu, on es fa un ús habitual. En canvi, no sol conèixer les dinàmiques del context administratiu, ja que és més comú que siguin els adults els qui s'encarreguin d'aquest tipus de tràmits. Per tant, al trobar-se en un context favorable per al valencià, resulta comprensible la seva consideració positiva respecte al reconeixement del mateix.

Relacionat amb aquest tema, és necessari conèixer quines són les causes principals per les quals els enquestats creuen que el reconeixement de l'idioma és aparentment escàs. Els resultats mostren que l'opinió majoritària és el poc suport que li presten les institucions polítiques. En concret, un $62,4 \%$ assenyala als polítics com la principal causa de la poca normalització del valencià (taula 4). Una crítica on l'edat torna a ser un 
factor decisiu ja que, a mesura que aquesta augmenta, el nombre de persones que donen suport a aquest argument creix.

No obstant això, si bé l'escàs nombre de polítiques lingüístiques és la causa més reconeguda, cal destacar l'ocorregut amb l'àmbit social. Encara que aquesta causa ha estat la segona més votada (taula 4), és la que ha sigut seleccionada per tots els grups d'edat i sexe. Els resultats demostren, per tant, que la mateixa societat es considera culpable de la situació de marginació que avui en dia viu el valencià.

D'altra banda, cal tenir en compte que la raó que ha estat menys valorada és l'empresarial ja que la mitjana amb prou feines suma un $16,14 \%$ (taula 4). Una dada sorprenent, tenint en compte que són els propietaris dels mitjans de comunicació els qui trien com ha de publicar-se el producte. Són els que, en primera instància, elegeixen els diferents formats, elements utilitzats i, per descomptat, l'idioma.

Finalment, un $21,57 \%$ dels enquestats, sobretot els menors d'edat, han tingut en compte altres motius (taula 4). Entre ells destaquen raons com la forta immigració que hi ha a Castelló, la normalització del castellà en tots els àmbits enfront del poc ús del valencià o la globalització.

Taula 4. Motiu pel qual el valencià no està reconegut a Castelló (\%)

\begin{tabular}{|c|c|c|c|c|c|c|c|c|c|}
\hline & Total & \multicolumn{2}{|c|}{$<\mathbf{1 8}$ anys } & \multicolumn{2}{c|}{$\mathbf{1 8 - 3 0}$ anys } & \multicolumn{2}{c|}{$\mathbf{3 0 - 5 5}$ anys } & \multicolumn{2}{c|}{$<55$ anys } \\
\hline & & D & H & D & H & D & H & D & H \\
\hline Polític & 62,4 & 20 & - & 75 & 87,5 & 66,7 & 83,3 & 100 & 66,7 \\
\hline Social & 57,6 & 40 & 66,6 & 25 & 62,5 & 66,7 & 33,3 & 100 & 66,7 \\
\hline Empresarial & 16,14 & - & - & 25 & 37,5 & 33,3 & - & 33,3 & - \\
\hline Altres & 21,57 & 60 & 33,3 & - & 12,5 & - & 33,3 & - & 33,3 \\
\hline
\end{tabular}

Elaboració pròpia

\subsection{Hàbits i preferències en el consum de premsa: lectors habituals i idioma}

Les dades revelen la idea que, a mesura que es va creixent, l'interès per la lectura de premsa va augmentant (taula 5). En canvi, en el grup dels més joves el consum d'aquest tipus de mitjà és pràcticament inexistent.

En sentit numèric, mentre que la mitjana de menors que llegeix premsa solament arriba al 33,6\%, el grup de 18 a 30 anys presenta una mitjana de $71,6 \%$, el de 30 a 55 un 91,8\% i, finalment, el grup de majors de 55 , arriba a un total del $87,5 \%$.

Taula 5. Hàbits en quant a lectura de premsa (\%)

\begin{tabular}{|c|c|c|c|c|c|c|c|c|c|}
\hline & Total & \multicolumn{2}{|c|}{$<\mathbf{1 8}$ anys } & \multicolumn{2}{|c|}{$\mathbf{1 8 - 3 0}$ anys } & \multicolumn{2}{|c|}{$\mathbf{3 0 - 5 5}$ anys } & \multicolumn{2}{|c|}{$<55$ anys } \\
\hline & & D & H & D & H & D & H & D & H \\
\hline Llegeix & 70,15 & 30 & 37,2 & 63,3 & 80 & 92,8 & 90,9 & 100 & 75 \\
\hline No llegeix & 28,75 & 70 & 62,5 & 36,3 & 20 & 7,1 & 9,1 & - & 25 \\
\hline
\end{tabular}

Elaboració pròpia

Aquest fet ja ha sigut constatat per molts investigadors de l'àrea de periodisme, entre ells, Andreu Casero en el seu estudi "Més enllà de la premsa: el consum de notícies dels joves en l'era digital», on assenyala 
dues raons principals que motiven aquesta realitat. La primera d'elles, és que la joventut identifica els diaris amb el món dels adults (Raeymaeckers, 2004. Citat en Casero,2012). La segona, la visió utilitarista que els joves veuen en la premsa, donat que creuen que quan els seus temes i continguts els afectin directament la llegiran, però mentrestant es mantenen allunyats en considerar els seus missatges i formats poc adequats a les seves necessitats i expectatives (Vanderbosch, Dhoets \& Van der Bulck,2009. Citat en Casero,2012).

Per altre costat, relacionat amb el consum de premsa i arribant a un dels pilars fonamentals d'aquesta investigació, és necessari saber si la societat de Castelló seria favorable davant d'una oferta de diaris escrits en valencià. Les dades extretes revelen que mentre un $62,2 \%$ dels enquestats donen suport a aquesta oferta, un $34,8 \%$ està en contra. En altres paraules, gairebé el doble defensa l'existència de diaris en valencià (taula 6).

Taula 6. Opinió sobre un augment de diaris en valencià (\%)

\begin{tabular}{|c|c|c|c|c|c|c|c|c|c|}
\hline & Total & \multicolumn{2}{|c|}{$<\mathbf{1 8}$ anys } & \multicolumn{2}{|c|}{$\mathbf{1 8 - 3 0}$ anys } & \multicolumn{2}{|c|}{$\mathbf{3 0 - 5 5}$ anys } & \multicolumn{2}{c|}{$<55$ anys } \\
\hline & & D & H & D & H & D & H & D & H \\
\hline $\begin{array}{c}\text { Deuria } \\
\text { augmentar }\end{array}$ & 62,2 & 90 & 37,2 & 54,5 & 80 & 64,2 & 45,4 & 100 & 50 \\
\hline $\begin{array}{c}\text { No deuria } \\
\text { augmentar }\end{array}$ & 34,8 & 10 & 62,5 & 45,4 & 20 & 35,7 & 54,5 & - & 50 \\
\hline
\end{tabular}

Elaboració pròpia

Tal com s'observa, igual que ocorria en punts anteriors, a mesura que l'edat augmenta, els enquestats es mostren més a favor d'una l'oferta de diaris en valencià. Solament hi ha una petita baixada en el grup de 30 a 55 anys, que suma una mitjana de $34,8 \%$ enfront del $67,25 \%$ del grup anterior.

Per altra banda, cal destacar les raons per les quals els enquestats creuen que no hauria d'augmentar l'oferta. Tal com demostren els resultats (taula 7), l'àmbit social torna a postular-se com una de les principals causes perquè no existeixin diaris en valencià. En concret, el $51,4 \%$ dels casos pensa que la societat prefereix llegir un diari en castellà en lloc d'en valencià.

No obstant això, la dada més destacable és el canvi pel que fa a la taula número 4. En aquesta, els enquestats consideraven que el valencià no era suficientment reconegut a causa del poc suport rebut des del Govern. En canvi, pel que fa a l'augment de l'oferta en valencià, solament un 18,2\% creu que és a causa de les poques subvencions i ajudes. Al contrari, el motiu que ha estat més votat és el que assenyala que un periòdic en valencià no és rendible per a les empreses, que ha sumat una mitjana de $60,4 \%$. 
Taula 7. Motius pels quals opina en contra de l'oferta de diaris en valencià (\%)

\begin{tabular}{|c|c|c|c|c|c|c|c|c|c|c|}
\hline & Total & \multicolumn{2}{|c|}{$<18$ anys } & \multicolumn{2}{|c|}{$18-30$ anys } & \multicolumn{2}{|c|}{$30-55$ anys } & \multicolumn{2}{|c|}{$<55$ anys } & 502 \\
\hline & & D & $\mathrm{H}$ & D & $\mathrm{H}$ & D & $\mathrm{H}$ & D & $\mathrm{H}$ & \\
\hline $\begin{array}{c}\text { La societat } \\
\text { prefereix el } \\
\text { castellà }\end{array}$ & 51,4 & 100 & 66,6 & 25 & 50 & 20 & 50 & 50 & 50 & 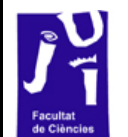 \\
\hline $\begin{array}{c}\text { Un diari en } \\
\text { valencià no és } \\
\text { rendible }\end{array}$ & 60,4 & - & - & - & 50 & 60 & 33,3 & 50 & 50 & $\begin{array}{l}\text { isocials } \\
\text { JNIVERSITAT } \\
\text { JAUME. I }\end{array}$ \\
\hline $\begin{array}{c}\text { No hi ha } \\
\text { suficients } \\
\text { subvencions }\end{array}$ & 18,2 & - & - & 75 & 37,5 & - & 33,3 & - & - & \\
\hline Altres & 12,4 & - & 33,3 & - & 12,5 & 20 & 33,3 & - & - & \\
\hline
\end{tabular}

Elaboració pròpia

\subsection{Interès en la premsa de Castelló}

Els resultats obtinguts en aquest punt demostren que, tal com assenyalen els índexs d'audiència de l'OJD, el diari amb major nombre de lectors a la província de Castelló és Mediterráneo (taula 8). En concret, aquest suma el doble d'audiència que els altres periòdics amb un 56,2\%. A més, és el que es troba present en tots els grups d'edat i sexes enquestats. Per contra, El Mundo, Levante de Castelló i Las Provincias contemplen un nombre mínim de lectors en comparació al diari capdavanter. De fet, Las Provincias solament és llegit per un home i una dona del grup d'edat de 30 a 55 anys.

Taula 8. Hàbits de lectura de l'oferta principal de diaris a Castelló (\%)

\begin{tabular}{|c|c|c|c|c|c|c|c|c|c|}
\hline & Total & \multicolumn{2}{|c|}{$<\mathbf{1 8}$ anys } & \multicolumn{2}{c|}{$\mathbf{1 8 - 3 0}$ anys } & \multicolumn{2}{c|}{$\mathbf{3 0 - 5 5}$ anys } & \multicolumn{2}{c|}{$<55$ anys } \\
\hline & & D & H & D & H & D & H & D & H \\
\hline Mediterráneo & 56,2 & 33,3 & 33,3 & 57,1 & 62,5 & 79,9 & 50 & 100 & 33,3 \\
\hline El Mundo & 23,3 & - & 33,3 & 42,8 & 12,5 & 30,8 & 33,3 & - & 33,3 \\
\hline $\begin{array}{c}\text { Levante de } \\
\text { Castelló }\end{array}$ & 23,12 & - & - & 28,6 & - & 23,1 & 33,3 & 66,6 & 33,3 \\
\hline Las Provincias & 11,9 & - & - & - & - & 7,7 & 33,3 & - & - \\
\hline
\end{tabular}

Elaboració pròpia

De nou, intentant contestar als objectius d'aquest treball, resulta necessari saber si els enquestats que afirmen llegir aquests diaris estarien disposats a consumir-los en valencià. Els resultats revelen que un $67,9 \%$ sí que es mostraria favorable, mentre que solament un $30 \%$ preferiria seguir comprant l'exemplar en castellà (taula 9).

Taula 9. Actitud davant de la compra del mateix diari en valencià (\%)

\begin{tabular}{|c|c|c|c|c|c|c|c|c|c|}
\hline & Total & \multicolumn{2}{|c|}{$<\mathbf{1 8}$ anys } & \multicolumn{2}{|c|}{$\mathbf{1 8 - 3 0}$ anys } & \multicolumn{2}{|c|}{$\mathbf{3 0}$-55 anys } & \multicolumn{2}{c|}{$<55$ anys } \\
\hline & & D & H & D & H & D & H & D & H \\
\hline Sí el compraria & 67,9 & 100 & 66,6 & 57,1 & 62,5 & 80 & 60 & 66,6 & 50 \\
\hline $\begin{array}{c}\text { No el } \\
\text { compraria }\end{array}$ & 30 & - & 33,3 & 28,6 & 37,5 & 20 & 40 & 33,3 & 50 \\
\hline
\end{tabular}

Elaboració pròpia 


\subsection{Interès en la premsa de Castelló}

Avui en dia, Internet ha canviat radicalment la forma de consumir informació ja que abans les persones depenien completa i únicament de la premsa, televisió o ràdio per conèixer allò que ocorria al món. Avui, en canvi, podem entrar a una multitud de pàgines web que donen una informació d'igual o de millor qualitat que els mitjans tradicionals. De fet, podria dir-se que Internet s'ha convertit en el gran mitjà de comunicació de masses del segle XXI gràcies al fet de ser un espai obert per a tots sense cap tipus de fronteres, ni tan sols idiomàtiques.

Arran d'aquesta idea, les dades d'aquest estudi revelen que un $78,8 \%$ dels enquestats veuen en Internet una oportunitat per a l'augment de la informació en valencià. Per contra, solament un $21,2 \%$ creu que l'oferta en Internet d'aquest idioma seguirà mantenint-se amb els pocs mitjans que hi ha en aquesta llengua, per exemple, Vilaweb o La Veu del País Valencià (taula 10).

Taula 10. Opinió sobre l'impacte d'Internet en l'ús del valencià (\%)

\begin{tabular}{|c|c|c|c|c|c|c|c|c|c|}
\hline & Total & \multicolumn{2}{|c|}{$<\mathbf{1 8}$ anys } & \multicolumn{2}{|c|}{$\mathbf{1 8 - 3 0}$ anys } & \multicolumn{2}{|c|}{$\mathbf{3 0 - 5 5}$ anys } & \multicolumn{2}{c|}{$<55$ anys } \\
\hline & & D & H & D & H & D & H & D & H \\
\hline Augmentarà & 78,8 & 90 & 62,5 & 72,7 & 80 & 85,7 & 72,7 & 100 & 66,7 \\
\hline No augmentarà & 21,2 & 10 & 37,2 & 27,3 & 20 & 14,3 & 27,3 & - & 33,3 \\
\hline
\end{tabular}

Elaboració pròpia

No obstant això, és necessari conèixer si realment la societat consumiria aquest contingut online en valencià. De nou, les dades revelen una posició favorable, però molt menor que en l'anterior punt. En aquest cas, el $65 \%$ consumiria informació en valencià en mitjans online front al $35 \%$ que no ho faria (taula 11 ).

Taula 11. Actitud davant del contingut online en valencià (\%)

\begin{tabular}{|c|c|c|c|c|c|c|c|c|c|}
\hline & Total & \multicolumn{2}{|c|}{$<\mathbf{1 8}$ anys } & \multicolumn{2}{|c|}{$\mathbf{1 8 - 3 0}$ anys } & \multicolumn{2}{|c|}{$\mathbf{3 0 - 5 5}$ anys } & \multicolumn{2}{c|}{$<55$ anys } \\
\hline & & D & H & D & H & D & H & D & H \\
\hline Consumiria & 65 & 70 & 37,5 & 54,5 & 80 & 71,4 & 63,6 & 75 & 75 \\
\hline No consumiria & 35 & 20 & 62,5 & 45,4 & 20 & 28,3 & 36,4 & 25 & 25 \\
\hline
\end{tabular}

Elaboració pròpia

Si s'analitza la variable dels anys, s'observa una important paradoxa a causa que, a major edat, major predisposició al consum d'informació en valencià de forma online. Així doncs, malgrat l'alt ús d'Internet que fan els joves, aquest no està enfocat al consum d'informació.

Els hàbits de consum d'informació dels joves han canviat radicalment en els últims anys, ja que solament el $28,8 \%$ del total d'aquest col-lectiu llegeix els diaris cada dia. Per contra, cada vegada han adquirit major protagonisme les xarxes socials. En concret, el 77,4\% dels joves d'entre 16 i 30 anys les usen per informar-se (Casero, 2012). Per tant, en aquest cas, la raó d'aquesta dada podria explicar-se, no com un rebuig al consum de continguts de mitjans en valencià per part dels joves, sinó com una postura 
contrària a consumir la informació a través de llocs web especialitzats en aquesta labor.

\section{Discussió i conclusions}

Així doncs, després d'analitzar els resultats obtinguts en la investigació, s'observa que les dues hipòtesis plantejades han quedat refutades.

En primer lloc, la societat castellonenca es caracteritza per conèixer i entendre perfectament el valencià així com per fer un ús considerable del mateix (H1). Si bé no sempre és l'idioma preferent a l'hora de parlar, llegir o escriure, sí que és emprat per tots els grups d'edat i sexe estudiats en alguna ocasió de la seva vida quotidiana.

A més, encara que són els joves els que més l'empren, s'ha corroborat com els adults, sobretot els majors de 55 anys, responen favorablement a l'ús del mateix. De fet, són aquells que més defensen la idea del valencià com una llengua útil i necessària.

Així mateix, pel que fa al reconeixement del valencià, mentre que els més joves opinen que l'ús d'aquest està suficientment consolidat a la província, a mesura que l'edat augmenta el judici es torna molt més crític i escèptic. Una actitud que suposa una important paradoxa, ja que encara que són els més majors els que menys usen el valencià, són alhora els que més defensen la seva utilitat i la seva falta de normalització. La raó principal que han assenyalat tots els enquestats com a causa de la posició de marginació que ocupa el valencià és el factor social.

Una qüestió que reforça la idea que l'actitud col-lectiva dels valencians segueix sent insuficient quant a la lluita per la normalització de cara a la seva pròpia llengua (Ferrando, 1990 i Castellano 2008). De la mateixa manera, la totalitat dels enquestats ha assenyalat a la societat com la principal culpable del fet que no hi existeixin més mitjans de comunicació, especialment diaris, en aquest idioma ja que, segons indiquen els resultats, es creu que la societat no vol aquest tipus de producte.

Un punt de vista que trenca radicalment amb els resultats obtinguts que mostren una sòlida i favorable actitud davant de l'existència d'una oferta de diaris en valencià a la província de Castelló (H2). No obstant això, cal tenir en compte diversos punts amb motiu de la seva importància.

En primer lloc, si es té en compte la variable de l'edat relacionada amb el consum de premsa, la recerca demostra que, a mesura que es va creixent, hi ha un major interès en aquest mitjà de comunicació. Estudis han demostrat que una de les raons per les quals els joves no llegeixen periòdics és que no s'identifiquen amb la informació que aquests publiquen (Casero, 2012). No obstant això, I'ús cada vegada major que fan d'Internet pot provocar que aquests mai arribin a consumir premsa en paper, doncs els seus hàbits ja s'han focalitzat en el consum a través de la xarxa. Un fet que no solament suposa un futur incert per a la premsa en valencià, sinó per a la premsa en general.

Per altra banda si l'edat es relaciona amb l'actitud enfront del valencià, són els joves els que més recolzen la idea que hi hagi un augment de diaris 
escrits en aquesta llengua a la província de Castelló. D'aquesta forma, encara que la seva relació amb el consum d'informació no és molt gran, es reforça el seu hàbit en l'ús del valencià. De fet, és tal el suport que s'observa davant d'una possible oferta en valencià, que la majoria dels enquestats no solament opina que aquesta hauria d'augmentar, sinó que afirmen que comprarien els diaris ja existents si estiguessin escrits en aquesta llengua.

Tal com demostren estudis d'audiències com I'OJD i els resultats d'aquesta recerca, els diaris més llegits a Castelló són Mediterráneo, El Mundo, Levante de Castelló o Las Provincias. No obstant això, aquest demostrat èxit d'audiència no implica que el model que ofereixen sigui el millor o el més correcte. Si bé és cert que en la cerca d'un motiu pel qual no existeix una oferta en valencià feta en aquest article, el principal resultat ha sigut que un diari en valencià no seria rendible, també s'ha demostrat l'expectació de la societat davant un periòdic escrit en la llengua del territori. El que demostra, per tant, que les persones, més que voler un diari en una llengua majoritària, allò que busquen és la qualitat de la informació, independentment de com hagi estat escrita.

Per últim, una idea a la qual cal donar especial atenció és a la d'Internet com a possible futur de la premsa en valencià. Segons reflecteixen els resultats, hi ha un punt de vista generalitzat molt positiu sobre aquesta qüestió. És més, l'edat no és un determinant en el consum de premsa online, doncs tant els joves com els adults consideren la xarxa com una de les millors opcions per consumir informació en valencià. Resulta, per tant, una postura que planteja una possibilitat d'aparent èxit per a l'existència de mitjans escrits en aquest idioma.

No obstant això, cal destacar que, posat que el tema central de la investigació està destinat a conèixer l'actitud de la societat davant d'un diari en paper en valencià, els resultats referents a Internet no tenen un valor determinant. Les dues qüestions incloses en aquest treball tenien com a objectiu saber si, en general, la societat es mostrava favorable davant el consum d'informació en valencià en Internet. Però, amb la finalitat de conèixer si aquesta actitud seria la que finalment complirien, seria necessari dur a terme un article molt més centrat en aquest aspecte i que tingués en compte les característiques d'aquest mitjà i la seva relació amb les formes de consum de la societat.

Així mateix, a manera de crítica, cal senyalar que, encara que les dades donen a conèixer una postura general sobre l'ús del valencià i hàbits de consum de premsa de la societat castellonenca, el nombre d'enquestes 71 en total - no és el suficient com per a poder tenir uns resultats complets i que atenguin a la total diversitat de postures existents a la província. Per tant, seria necessari ampliar el camp de recerca i incloure un nombre major d'enquestes.

Finalment, un aspecte important de la investigació és que, encara que aquesta buscava entendre l'actitud dels consumidors, seria necessari expandir la cerca de la raó de la inexistència d'un diari en valencià a altres àmbits. Sobretot, a l'empresarial, doncs són els propietaris i treballadors els qui en primera instància decideixen com serà el producte que finalment 
serà difós. A més, tal com s'ha vist al llarg del treball, l'àmbit polític ha estat causa central, tant de l'escassa normalització del valencià a la Comunitat Valenciana, com de la seva poca utilització en els mitjans de comunicació.

Per tant, un tema interessant seria investigar quins són els motius pels quals, avui en dia, el País Valencià segueix sent una de les comunitats autònomes on menor reconeixement es fa de la seva llengua pròpia. Aquella que, en definitiva, forma part de la seva història, cultura i identitat.

\section{Bibliografia}

BELTRAN, A (2009): "La sociedad valenciana y los medios de comunicación», Zeitschrift für Katalanistik 22 (315-328).

CAStellano, E. (2008): «Situació del valencià als mitjans de comunicació. Un bon moment per al canvi d'actitud». Llibre Blanc de l'ús del valencià. (251-272).

CASERo, A (2012): «Más allá de los diarios: el consumo de noticias de los jóvenes en la era digital» Comunicar, 39 (151-158).

Conselleria d’Educació, Cultura I Esports de la Generalitat Valenciana (2010): "Coneixement i ús social del Valencià».

FERRANDO, A (1990): La llengua als mitjans de comunicación, Universitat de València, Institut de filologia Valenciana.

INFORMACIÓN I CONTROL DE PUBLICACIONS (2012): «Información general sobre la difusión de diarios de información general».

MARTínez, F. (2010): Periodisme contra les cordes. El valencià als mitjans de comunicació, Denes Editorial, València.

RAEYMAECKERS, K (2004): «Newspapers Editors in Search of Young Readers: Content and Layout Strategies to Win New Readers» en CASERO, A (ed.) (151-158).

VANDERBOSCH, H I altres (eds.) (2009): «News for Adolescents: Mission Impossible? An Evaluation of Flemish Television News Aimed at Teenagers» en CASERO, A (ed.) (151-158).

VIÑAS I SALES, J. (2008): «Periodisme de proximitat, la clau de vertebració social», Plataforma Interuniversitària de la Premsa Comarcal, Primera Trobada (2010), Associació Catalana de Premsa Comarcal i Local.

ZABALATA, I i altres (eds.) (2011): "Volumen económico y estructura de los medios de financiación de los medios locales en catalán, euskera y gallego", en CASERO, A i altres (eds.) (2012): La prensa ante el reto digital. Oportunidades y Riesgos en un escenario cambiante. XI Congreso de la Comunicación Local, Universitat Jaume I, Castelló. 